\title{
EDUCATION ARTICLE
}

\section{Cooperative behaviour in theory and practice: leading undergraduate research in behaviour mathematical biology}

\author{
Jonathan T. Rowell* and Jan Rychtár \\ Department of Mathematics and Statistics, The University of North Carolina at Greensboro, \\ Greensboro, NC, USA
}

\begin{abstract}
The US National Science Foundation has promoted the early integration of undergraduate students into academic research environments by funding activities such as the Research Experiences for Undergraduates (REU) programs. Here, we discuss the operation of the first year for one REU site held on the campus of the University of North Carolina at Greensboro. Eight students from across the country were brought together for a 10-week summer programme in mathematical biology to work on research topics related to the establishment of cooperative behaviour. The students were paired in four teams, which approached the dynamic tension between cooperation and defection from a variety of mathematical and contextual perspectives. Two projects employed agent-based models on lattice environments: the first consisting of sparse populations of mobile individuals and the second featuring age-structured populations, historydependent fitness, and the possibility of kinship recognition. A third project looked at the evolutionary dynamics of behavioural frequencies in a model of society comprised of three social strata. The final project focused on the ecological range distribution of non-cooperative, cooperative and kleptoparasitic populations in heterogeneous resource environments. We describe both the general results of the students' research efforts and our observations on the efficacy of several enrichment activities provided to the students over the course of the REU summer.
\end{abstract}

Keywords: prisoner's dilemma; undergraduate research; cooperation; social behaviour; ecology

\section{Introduction}

Cross-disciplinary interactions are becoming increasingly common within the STEM fields, and mathematics and statistics play a special role providing not only tools of analysis but also a means of communication across disciplines. In this changing research environment, it is ever more important that undergraduate training reflect this reality in the curriculum and via external opportunities. The Mathematical Association of America (MAA) released a report, 'Undergraduate Programs and Courses in the Mathematical Sciences: CUPM Curriculum Guide 2004', that outlined various ways to improve quantitative literacy among undergraduates. One of these approaches called for incorporating students in interdisciplinary research projects to develop contextual quantitative skills for situations not easily replicated in a classroom setting (Ganter, 2003). There are also ancillary benefits to the student researchers, including a positive influence on both overall learning while in college and decisions to pursue postgraduate study (Lopatto, 2010; Russell, Hancock, \& McCullough, 2009).

* Corresponding author. Email: jtrowell@ uncg.edu 
Thanks to funding from the National Science Foundation (NSF), the University of North Carolina at Greensboro (UNCG) now offers a Research Experience for Undergraduates (REU) programme for students to engage in active research in mathematical biology. This paper describes the operation of our programme in its maiden year and details four projects undertaken by participating students, each of which involves a different interpretation of the classic problem in game theory known as the prisoner's dilemma (see e.g. Broom \& Rychtár, 2013, Ch. 4) - more generally framed as the question of the evolution and maintenance of cooperation.

UNCG's REU programme in Mathematical Biology is administratively run through the university's Department of Mathematics and Statistics. The PI and co-PI are both faculty within the department and maintain active research in the fields of mathematical biology, game theory, ecology and evolutionary biology. Each faculty member also has an existing record of working with undergraduate researchers up to and including the peer-reviewed publication process. In addition to the principal investigators, two graduate students (one in mathematics, one in behavioural ecology) staffed the programme and led enrichment sessions on programing, reviewing literature, writing a curriculum vitae and application essay, and other skills relevant to success at the graduate level. A third faculty member from the Biology Department was a senior personnel for the grant. He lectured on the biology of bees and contributed to and provided biological motivation for two of the projects.

Our REU offered a 10-week summer residential programme that covered boarding, travel, and stipends for students as well as post-REU support for conference travel and publication costs. We formally advertised the programme during mid-spring 2014 immediately following the formal award notification from the NSF. For the 2014 programme, eight participating students were selected from a national pool of candidates, five of whom came from institutions either where STEM research was not a primary focus or where there was no terminal degree-granting programme in the mathematical sciences.

In the programme's first year at UNCG, students worked in pairs on four distinct research projects pertaining to the evolution of cooperation. Two projects approached the topic from an agent-based simulationist perspective. In one of these projects, the students studied the movement and clustering behaviour of a finite population of mobile agents who traversed a sparsely populated network of sites and played a variation of the prisoner's dilemma with each other upon encounter. The second related project examined a widespread but sedentary population whose game interactions set propensities for mortality and replacement within an age-structured community. The third research project involved a social dynamic model where cooperation and defection translated to alternative behavioural traits played by three social classes. The students investigated how asymmetries within the group interactions led to different social compositions. The final student project explored an ecological interpretation of cooperation and exploitation. The students modified an existing model of spatial population dynamics to describe three populations with stereotypical expressions of selfish, cooperative, and exploitative behaviour as represented in their respective functional descriptions of per capita fitness. Below we describe the operation of our REU site and provide descriptions of the motivation, background, and results for each of the four projects.

\section{The program}

Our REU programme in mathematical biology is held on the campus of UNC-Greensboro, a member institution of the University of North Carolina system. The Department of Mathematics and Statistics offers undergraduate and graduate instruction in both fields, and it has recently begun a Ph.D.-granting programme in computational mathematics. The 
principal investigator, Dr Jan Rychtár, is a senior member of the faculty and annually coordinates the UNCG Regional Mathematics and Statistics Conference, while the co-PI, Dr Jonathan T. Rowell, holds a tenure-track position within the department and has significant prior experience working in the biological sciences. Dr Olav Rueppell of the Department of Biology also served as a senior personnel member on the REU grant. Our REU identifies three programme goals. We seek to involve a diverse group of undergraduate students in research and to improve their general scientific skills and confidence in same in preparation for graduate school and/or technical careers. We also aim to expose undergraduates to opportunities in mathematics and to strengthen efforts at recruiting and retaining women, minorities and students from schools with limited STEM emphasis. Our final objective is to generate new mathematical knowledge in the areas of mathematical biology and applied mathematics.

For its first year, the programme selected eight students from diverse backgrounds out of a pool of 29 applicants. Selections were based upon academic potential, clear interest in our REU programme and our mission to offer opportunities to under-served groups. This cohort was gender-balanced with four male and four female students. In addition, three out of eight students came from under-represented minorities, including African-American and Hispanic students. Seven of the students lived in a suite of rooms provided by the university's residence halls, while one locally based student opted to live off campus. Student ages ranged from 18 to 22, encompassing freshmen, sophomores, juniors, and non-graduating seniors, and their prior course work in mathematics and statistics varied extensively. Five students were from institutions where there was no terminal degree offered in the mathematical sciences. Three students were in departments that offered master's degrees, while two students came from schools offering only a bachelor's degree in mathematics.

The 10-week programme consisted of two distinct phases. In the first two-week period, the students underwent a broad training suitable for the preparation of mathematical biologists (Table 1). Morning sessions covered technical subjects such as programing in Matlab and typesetting with $\mathrm{BT}_{\mathrm{E}} \mathrm{X}$, while the afternoons were devoted to instruction in a number of topics in mathematics and biology as well as general academic skills. A doctoral student within our department was responsible for the morning sessions, and he offered programing and mathematical consultation during the research phase of the programme. The co-PI provided the bulk of the mathematical and biology training in the afternoon. A second graduate student, now enrolled in a doctoral programme in behavioural ecology at Cornell University, led discussions on reviewing the literature, academic writing and other skills. In addition to this instruction, the students undertook daily mini-projects that encapsulated the lessons of the day and in which they would need to work together to prepare a finalized report.

After two weeks of training, the students interviewed in one-on-one sessions to discuss their interests in projects and partners, with the final determination of assignments made by the PI and co-PI. For the remaining eight weeks of the programme, the students worked on their respective assignments. They were required to give daily elevator-talk synopses of their work as well as weekly formal presentations. In keeping with the goal of introducing the students to a complete biomathematics research environment, one graduate assistant also organized a weekly journal club in which each participant led a discussion on a paper of their choice.

The REU programme culminated with student presentations in a formal symposium attended by faculty from across the university. Research and writing have continued for each team since the conclusion of the summer, with presentations at several conferences 
Table 1. Training topics. Lectures were provided in five main areas during the first two weeks of the REU programme, with four classes per day. Daily mini-projects required the use of all of the day's lecture materials.

\begin{tabular}{|c|c|}
\hline Area & Course topics \\
\hline Matlab & $\begin{array}{l}\text { Matlab Basics, Arrays, Vectors and Matrices, Comparisons, } \\
\text { Searching, and Controls, Scripts and Functions, File Management, } \\
\text { Plotting Data, Structures }\end{array}$ \\
\hline $\mathrm{LAT}_{\mathrm{E}} \mathrm{X}$ & $\begin{array}{l}\text { Creating a Document, Arrays and Matrices, Sections and Tables, Bibliography } \\
\text { and References, Text Environments, Figures, Table of Content }\end{array}$ \\
\hline Mathematics & $\begin{array}{l}\text { Intro to Game Theory, Replicator Dynamics, Linear Algebra and Leslie Matrices, } \\
\text { Ideal Free Distributions, Ordinary Differential Equations, Partial Differential } \\
\text { Equations }\end{array}$ \\
\hline Biology & $\begin{array}{l}\text { Gene Frequency and Fitness, Biology of Bees (2-part), Life History Evolution, } \\
\text { Optimal Foraging Theory, Community Assemblages }\end{array}$ \\
\hline General Skills & $\begin{array}{l}\text { Finding Sources, Reading and Extending Journal Articles, Editing and Critiquing } \\
\text { Colleagues, Communicating Ideals, Organizing Proposals and Plans of Study }\end{array}$ \\
\hline
\end{tabular}

slated for the fall and spring semesters. For each of the four projects, submission for peerreviewed publication either has occurred already or is expected in the near term.

Our programme featured a vertical integration of responsibility and development for students, graduate assistants and investigators. The students were active participants during course discussions, and these dialogues led to the genesis of two of the research projects that were ultimately chosen. They also developed an internal support network within the cohort and aided one another with both research and non-academic matters. Participating students gained access to multiple points of view on the academic enterprise as each investigator and assistant were at a different stage along their respective career paths. Our biology graduate assistant was given leeway to develop the journal club and to work with the students in developing their individual curricula vitae and application packets for graduate school or external employment. Her insights were particularly useful because her recent life experiences paralleled those encountered by the participants. This assistant had previously done research with the co-PI as part of a university honours programme at another campus, had worked for several years after graduation at remote field sites and as a research technician, and had just recently been admitted into a doctoral programme in behavioural ecology.

Each mathematics faculty member served as the primary supervisor for two of the four projects and met daily with the students. The PI coordinated a number of enrichment opportunities such as weekly guest lecturers from departmental faculty, visits to other institutions within the state and hosting REU students from Winthrop University. The co-PI oversaw student-centric matters such as move in, campus orientation and the initial training period. Lastly, both faculty members arranged social excursions for the students including hiking, kayaking, a museum visit and music.

\section{The projects}

The prisoner's dilemma is a classic problem in game theory (see e.g. Broom \& Rychtár, 2013, Ch. 4) in which two arrested individuals are each given a choice between confessing to a committed crime or remaining silent. By remaining silent - and thus cooperating 
Table 2. Prisoner's Dilemma. Each player has a choice between cooperating with their partner (remaining silent) or defecting (confessing). The combination of choices results in a pair of pay-offs representing the length of incarceration for Player 1 and Player 2, respectively. The socially optimal pay-off derived from mutual cooperation $(-10)$, cannot be achieved rationally because the Defect strategy always results in a better pay-off regardless of the other player's action. This consequently results in the worst possible joint outcome $(-20)$.

\begin{tabular}{llc}
\hline Player 1 & \multicolumn{2}{c}{ Player 2 } \\
\cline { 2 - 3 } & Cooperate & Defect \\
\hline Cooperate & $(-5,-5)$ & $(-15,-2)$ \\
Defect & $(-2,-15)$ & $(-10,-10)$ \\
\hline
\end{tabular}

with one another - the two prisoners could escape punishment with only minor sanctions. If either confessed during interrogation, however, collectively harsher criminal penalties would be imposed. Because confession may lead to a reduction in one's own sentencing in either circumstance, each prisoner independently finds it advantageous to defect from their partner and confess to the crime (Table 2).

From a larger philosophical perspective, the prisoner's dilemma invites the question of how cooperation and in-group honesty could arise or be maintained given any social system's vulnerability to exploitation by bad actors ('Defectors'). This conundrum has been raised in both economics and evolutionary game theory, and despite suggested remedies like Tit for Tat stratagems and ethological or morphological constraints that effectively bar exploitative behaviours, it remains an open area of debate. In the four projects detailed below, our student teams each worked on problems of cooperation using different mathematical approaches and by framing their questions in different contexts.

\subsection{Mobile populations}

The first student project was supervised by Dr Jan Rychtár and concerned a system of discrete agents operating within a sparsely populated network of patches. The project focused on how these agents moved about the network and formed aggregations. As with many agentbased simulation studies (e.g. Broom, Hadjichrysanthou, \& Rychtár, 2010; Lieberman, Hauert, \& Nowak, 2005), the project model involves stochastically driven events (e.g. movement, competition) in the lifespan of an individual agent. The distinguishing feature of the research conducted here was the mobility of the agents. Each agent was labelled as either a Cooperator or Defector, the designation of which controlled both movement rule motivations and any interactions between agents. Interaction contests between different individuals were resolved under payoffs derived from a variation of the classic prisoner's dilemma.

The first task for the two students assigned to this project was to review select literature that explained how an important code component, called the Gillespie Algorithm (Gillespie, 1976), controlled the timing and order of stochastic events within the program model. The students next had to study previously written code and learn how to incorporate specific design features (e.g. movement) within their own work. By summer's end, the research team had achieved a working code that ran simulations for populations residing within a 'ring-world' network and began to consider toroidal lattice network environments. 
Collectively this was our youngest team during the summer, and a number of difficulties and challenges faced by this pair of students. Understanding existing code proved to be a source of particular difficulty, and both the faculty supervisors and graduate assistants expended considerable time helping the students overcome this obstacle. Poor documentation of early coding attempts by the students also led to several stages of development that had to be repeated. As we worked with the students over the course of the summer on reading the literature, programing, and time management, they came to understand the expectations typical for an active research group.

The project achieved limited results by the end of the REU programme, however; both students continued to work on the project during the fall semester and were able to expand their findings to a more fully fleshed out version of results. The students investigated how various parameters of the simulation influenced the evolution of cooperation. We found that both greater mobility and larger neighbourhood size inhibit the evolution of cooperation because it allows the defectors to find the cooperators faster and exploit them more. These updated results were presented at the 2014 BEER Symposium held at the Colleges of Claremont, the 2014 International Conference on the Advances of Interdisciplinary Statistics and Combinatorics held at UNCG, and the 10th UNCG Regional Mathematics and Statistics Conference. The team's findings are included in a paper currently in submission.

\subsection{Age-structured populations}

The second project, also directed by Dr Rychtár, studied the fixation rate of cooperation within an age-structured agent-based network. This project derived some of its motivation from the work of Dr Olav Rueppell, a member of UNCG's Department of Biology and a senior personnel on the REU grant. Like many other animals, bees have distinct life phases (pre-reproductive, reproductive and post-reproductive) in which interactions vary with respect to the age of individuals, and that the duration of these phases was subject to selection pressures. This model shared many features with the previous project (e.g. agents that could be either Cooperators or Defectors), but the system transpired on a two-dimensional lattice network of sites and each agent was fixed at a particular location. Individuals were subject to aging and mortality events as well as reproduction and competition for resources with individuals in neighbouring cells. The propensity of these events was influenced by an individual's fitness score, itself a function of the present and historic compositions of its neighbourhood.

This was the most technically demanding of the four projects we supervised in the 2014 summer. After a number of early tests of various stage structures, the team settled upon a life history that consisted of one time unit for the pre-reproductive stage, three time units for the reproductive stage and one time unit for the senescent/post-reproductive stage. This scenario is consistent with the life history stage proportions in humans (Nichols et al., 2006). As part of the programing, the students also considered the size of the neighbourhood with which an individual could interact, defined as occurring within a radius of $1-4$ sites from the individual's position (Figure 1).

The team continued to experiment with their model throughout the summer and ultimately added additional features to the basic simulation. First, they introduced mortality events at each age. Then they implemented the dependence on historic information for the fitness valuation. A final iteration of their model incorporated a kinship recognition rule that modulated how much benefit was given by a cooperator. After extensive simulations were performed under various conditions, the students exported their data for statistical analysis of the fixation probabilities for cooperative behaviour. 

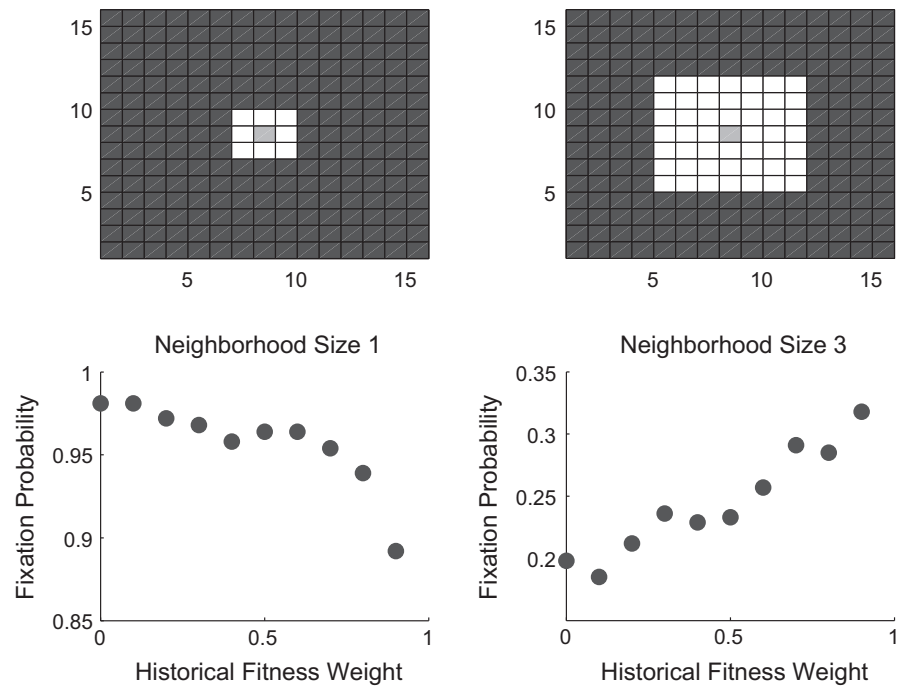

Figure 1. Neighbourhood size and fixation probabilities in age-structured models. Individuals can have interactions with other locations at varying distances. Examples shown are for neighbourhoods of size $n=1$ (upper left) and $n=3$ (upper right). The response of the fixation of cooperation to historical fitness weight varies with neighbourhood size. The probability decreases in a small neighbourhood (bottom left) but increases in a larger neighbourhood (bottom right).

The team discovered that fixation of cooperation occurred with a higher degree of likelihood than initially surmised. One of the strongest explanations that we could put forward was that this was the result of a mass-scale effect that would be absent from a classic matrix game approach. Direct competition to colonize empty cells within the network really only occurred at the boundary between subpopulations. Once cooperators established a small cluster by random circumstances, the cluster exerted a net positive effect on its peripheral members that overwhelmed any cost or disadvantage incurred during competition with defectors.

This emphasis on the interactions at the boundary of clusters also explained other results. The students determined that the probability of fixation for cooperation decreased with the size of the interaction neighbourhood. Larger neighbourhoods broadened the area considered peripheral and drove the model dynamics towards a standard mean-field approximation that would reduce to the classic non-structured prisoner's dilemma game. Neighbourhood size also mediated the effect on the fixation probability when increasing the weight of historical interactions (Figure 1). In small neighbourhoods $(n=1)$, the fixation probability declined as greater weight was given to historic interactions. In larger neighbourhoods $(n=3)$, however, the fixation increased with historical fitness weight. This systemic 'memory' also prolonged the average number of generations required to reach fixation.

Although the workload was unequally shared, this pair of students was perhaps the most cohesive in its operation, and their team exhibited the least internal friction over the course of the summer. As was common with most of the research partnerships, the students entered the programme with different motivations. One student had previously engaged in research under Dr Rychtár in the summer prior and was primarily interested in continuing to expand her personal awareness of the breadth of mathematical fields and available opportunities. The other student was eager to achieve publishable results and proved to be very capable, emerging as a natural leader within the larger REU cohort. 
The two team members left our programme having learned about running massive simulations and data exportation. As a final technical element in their training, these students also learned how to convert simulation results into animated visualizations for inclusion in presentations. Both students spoke on the project at UNCG's 2014 Regional Mathematics and Statistics Conference, and one did likewise at the 2015 Joint Mathematics Meeting in San Antonio. We anticipate that a manuscript discussing this project and its findings will be submitted for peer-review in early spring 2015. Additionally, we can report that for one of the students, the REU programme changed her aspirations and that she now wants to pursue her $\mathrm{PhD}$, and specifically here at UNCG.

\subsection{Social dynamics}

Under Dr Jonathan T. Rowell's supervision, the third project regarded the contest between cooperation and defection as a question of behavioural responses amid shifting social compositions. Prior research into the trustworthiness of public signals had shown that one could obtain results that diverged from classic game theory outcomes when there was a mixed-constituent audience or multiple players involved (Rowell, Ellner, \& Reeve, 2006). This project adapted that idea to describe the behavioural changes within a society composed of three interdependent classes (taxpayer elites, government and law enforcement, general citizens). Members of each class had a binary choice of actions for dealing with society at large (e.g. being charitable or stingy with resources) that could be equated with either cooperation or defection according to an external assessment of what constituted a just or ideal society. Our goal was to determine the underlying structural dynamics of these models and, secondarily, the conditions necessary to maintain a utopian social archetype where all classes adopted their respective equivalent of 'cooperate'.

The student team that was chosen for this project consisted of a freshman and a junior. The students first learned to work with differential equations from a modelling perspective, and then they studied how replicator dynamic equations were derived from standard matrix games. Replicator equations are a mathematical tool that describes how the frequencies of traits in a population, e.g. cooperation, evolve over time (Hofbauer \& Sigmund, 1988). The strength of selection is the expected difference in fitness of alternate traits under current social conditions, while the rate of encounter between contrasting behavioural types is proportional to the trait variance, i.e. the frequency $x(t)$ of trait $A$ obeys

$$
x^{\prime}(t)=\left(f_{A}(C)-f_{B}(C)\right) x(1-x) .
$$

After absorbing this foundational material, the students developed a matrix game that encapsulated a number of social features that we were interested in testing. These features included such aspects as the levels of wealth transfer during civil unrest (rioting), effectiveness of law enforcement at different levels of aggressiveness and non-utilitarian social values that favoured living in a utopian society. The team went through several iterations of model design before reaching a balance between the number of available parameters and tractability. Most of the model's pay-off structure was based upon a zero-sum game of wealth transfer; however, we included two factors that were either psychological or valuedriven in nature. One factor addressed the aggravation endured by citizens dealing with a more intrusive government, while the second factor was the cultural importance placed on maintaining a 'perfect' utopian society.

Once the model was finalized, the students converted the matrix game pay-offs to the corresponding system of replicator equations. The team explored several analytic questions such as determining the stability of archetypal (monomorphic) societies under different 
parameter ranges, as well as the general presence and stability of other external equilibria. They also calculated a condition for the existence of internal equilibria where all social classes maintained an intermediate level of cooperation. Concurrently, the team developed Matlab code to run numerical simulations that could generate evolutionary trajectories of society and corroborate our analytic findings.

The students discovered a handful of possible outcomes for social composition. Charitability was lost under most parametric combinations without a utopian preference, and society either defaulted to a dystopian outcome or cycled through periods of oppression, relaxation, rioting and restoration of order (Figure 2(A)). Social ideals could stabilize the utopian archetype, but that alone did not eliminate the possibility of other attractors within the system. Consequently, the trajectory of societal evolution remained initial condition dependent (Figure 2(B)).

This project differs from the previous two as it arose from discussions held during the first two weeks of instruction. The two students that were chosen did not have extensive mathematical backgrounds; however, the younger partner was very ambitious in regards to producing a paper from the summer's work. The older student had previously performed summer research with Dr Rychtář and was primarily interested in the general experience and in further developing her communication skills, particularly in the area of public speaking. There was some friction over the resulting division of the workload as the second student lived off-campus for reasons external to the REU programme and was essentially unavailable in the evenings for continued work. Ultimately, the team adapted and actually addressed each member's weaknesses in a constructive fashion, with the younger student learning to work within the partnership constraints and helping the other student improve communication skills. The younger student came to play a similar supporting role within the larger REU cohort.

The team had an initially strong start to their research topic, but progress stagnated midway through the summer. They mastered the mathematical content fairly well and had a good working model soon thereafter. Coding introduced some difficulty when it came to managing data flow and running simulations across multiple parameter combinations, and documentation was sometimes lacking. In addition to schedule issues, the team also faced a peculiar challenge in that they had to navigate background literature from the fields of sociology, psychology and criminal justice.

The students presented their work at the programme's closing symposium. The project achieved most of our initial goals. There remained a number of extensions that we were interested in exploring with the model, however, and one of the students has continued to work on the project with Dr Rowell. We anticipate finalizing our manuscript by late Spring 2015 with presentations to follow.

\subsection{Cooperation and kleptoparasitism}

The final project, also directed by Dr Rowell, placed cooperation and defection in the context of theoretical ecology and per capita fitness functions. A number of papers have recently established a framework for studying the dynamics and spatial distributions of populations capable of adaptive movement (Cosner, 2005; Rowell, 2009; Rowell, Ellner, \& Reeve, 2006). Applying the concept of the ideal free distribution (Fretwell \& Lucas, 1969) to local migration, the base model governing a population's density $u$ is

$$
\frac{\partial u}{\partial t}=-k \nabla \cdot(u \nabla f)+r u(f-\mu / r),
$$




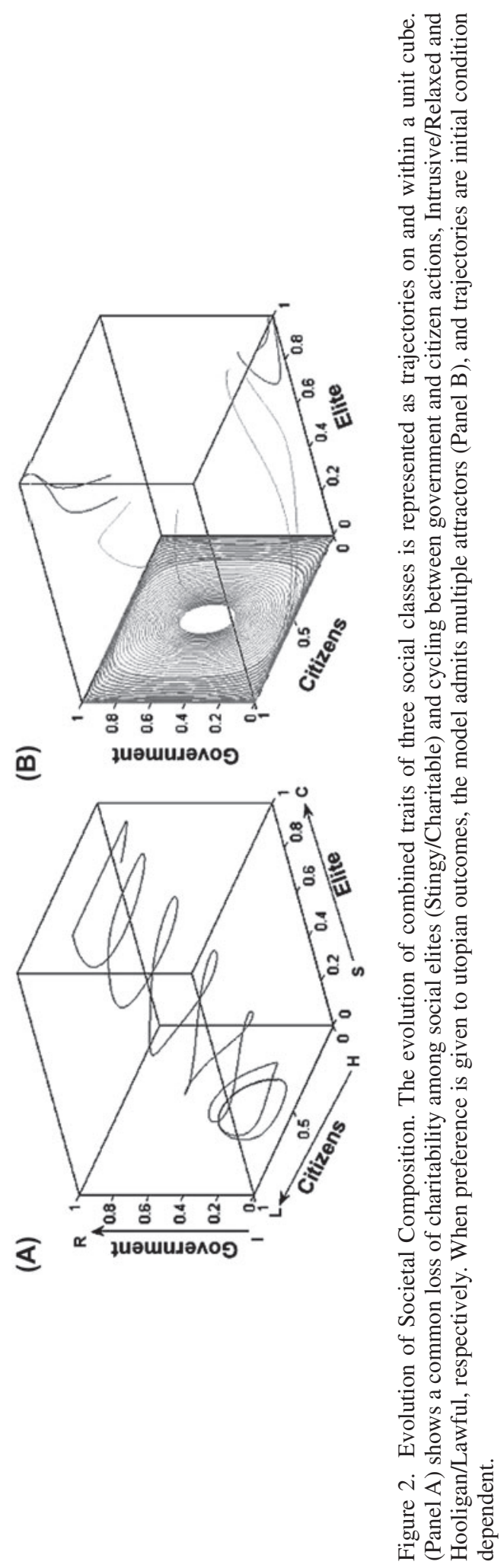


Table 3. Stereotypical functional responses. Fitness is proportional to resources $R$. Self-reliant or selfish fitness strictly declines with density $u\left(f_{S}\right)$, while the contributor function has an Allee effect under which fitness initially increases with density $\left(f_{C}\right)$. Resources are half-depleted when $u=h$ or $u=\alpha$, respectively. The kleptoparasite differs in that it steals a portion of resources, $\theta$, gathered by heterospecifics (density $v$, fitness $f_{v}$ ). Encounters between parasites and the host population are a mass-action process occurring at a rate proportional to $u v$, with $v$ the selfish or contributor density, as appropriate. The host fitness is reduced correspondingly.

\begin{tabular}{lcc}
\hline Self-reliant & Contributor & Kleptoparasite \\
\hline$f_{S}=\frac{R}{u+h}$ & $f_{C}=\frac{R u}{u^{2}+\alpha^{2}}$ & $f_{K}=\theta v f_{v}$ \\
\hline
\end{tabular}

where movement or flux is in the direction of greatest immediate increase in fitness, represented by $f$. Here $k$ is a measure of sensitivity to environmental information, and $r$ and $\mu$ are the metabolic conversion and mortality rates of individuals, respectively. For this project, we considered three variations of a fitness function $f$ representing performance in recovering resources from the environment (Table 3). The three variations are stereotypical expressions of selfishness, cooperation and exploitation. These functions drive the local population dynamics and also constitute public information with which individuals could optimally direct their movement for improved fitness.

As part of their research responsibilities, the students investigated both the local dynamics generated by these functional responses and the larger spatial models. The students began with a study of the literature of the original adaptive movement problem and the concept of a fitness landscape. They then implemented model Equation (2) for the three functional variations found in Table 3 and further extended the model to account for both pairwise and community-wide competition. Programing proceeded in two phases. The students first wrote simulation code that addressed the localized dynamics of the model and then subsequently incorporated spatial dependence and movement processes. A natural division of labour emerged within the team where one student focused on the invasibility and coexistence conditions for kleptoparasites, while the other student studied the competitive interactions between selfish and cooperative individuals, as well as the community assemblage where all three groups were present.

The project produced a number of important results. There is a common analytic condition for kleptoparasitic invasions without explicit regard to the specific form of the host population's fitness function. Such invasions yielded dynamically stable equilibria (both local and spatial) when kleptoparasites invaded self-reliant host populations. When the host population was comprised of contributors, however, stability became resourcedependent. Invasions were disruptive in regions of high resource availability because they promoted an expanding boom-bust cycle within the community that eventually crossed a non-recoverable threshold for the host contributors (Figure 3). These oscillations were damped under intermediate resource levels, however, and led to stable coexistence. Additionally, contributor and self-reliant populations proved to be mutually exclusive of one another unless there was some variation in interference strength (cf. Rowell, 2010). By the end of the REU programme, the students had begun to examine whether mutation between these two populations could overcome this exclusionary result. Initial findings held that only unnaturally large mutation rates could produce an attracting coexistence state; however, the conclusion of this project did suggest worthwhile extensions suitable for our 2015 student cohort related to the establishment of cooperation via a step-wise mutation process. 


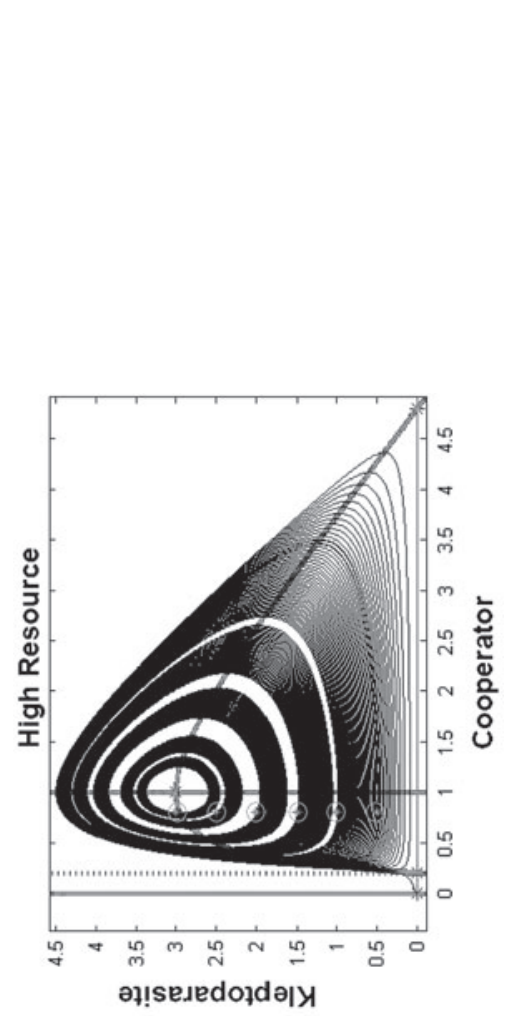

ส

$\therefore \frac{0}{00} \frac{\dot{m}}{\mathrm{G}}$

卷 :

巴

象

这

过志

ت马ु

它

综部

งิ

है

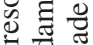

6.

츨

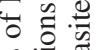

结

जः

$\exists 00$

言

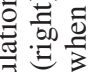

完它

讨

里

造言

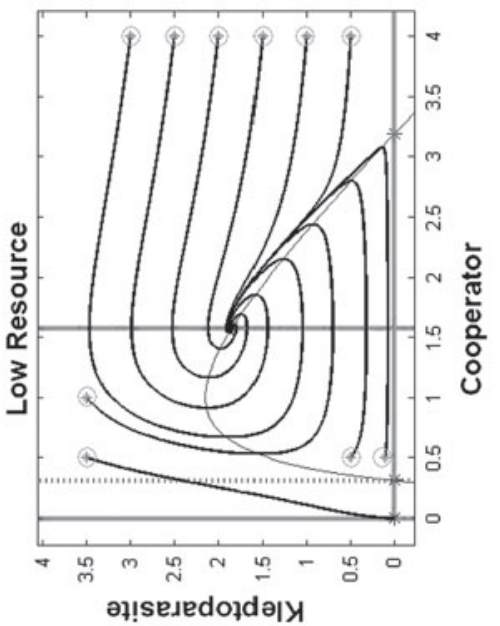

0.

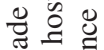

跤

造 :

政

근믕

的

步它

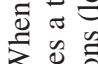

$>$.

훌 흔

卷 중

渮.

啳

요를

웡

처유

농

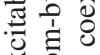

圷造

$\dot{m} \frac{\pi}{\omega}$

言芯 灵

4 
The idea of approaching the evolution of cooperation from an ecological perspective arose from discussions during the initial two-week training phase, and the project was a popular choice among the students. The two students who were ultimately selected for this project were both seniors motivated towards achieving publishable results. Although additional specific training was required, each student already had some pre-existing familiarity with ordinary and partial differential equations. The students alternated between independent and collaborative work during the summer. Consequently, they were each able to attack specific research questions. This approach facilitated the progress of research, but their independent work occasionally resulted in the exchange of coding sections that did not always mesh when they reconvened to discuss the overall project. Internal team disputes primarily revolved around alternate work schedules, but overall the students functioned well together. One common hurdle faced by both students was the need to immerse themselves in biological literature and to develop their manuscript writing style with that audience in mind.

The two students involved with this project presented a joint talk at our end-of-summer research symposium, and they planned an active slate of presentations at several student and professional conferences. In total, the students have given talks at the 2014 AMS Southeast Sectional meeting, the 2014 NIMBioS Conference in Tennessee and the 2015 joint AMS-MAA meeting. We anticipate one student will also present at the MAA Southeastern sectional meeting in 2015. Revision of the manuscript resulting from this project proceeded throughout the fall semester, and the article is in submission at the time of this writing. As a final note, both students felt positive about their experience at the UNCG REU, and they are presently applying to various graduate programmes around the country.

\section{Evaluation of the REU programme}

The UNCG REU was evaluated both internally by the faculty, graduate student assistants, and participating undergraduates, and by an external evaluator Dr Suzanne Lenhart, an associate director for Education and Outreach of the National Institute for Mathematical and Biological Synthesis (NIMBioS), Knoxville, TN. The evaluation of the programme was both formative and summative in nature, in that the data collected was intended to gain feedback about the quality of the current programme and also to inform next year's programme. The overall design drew from the evaluation procedures of the REU programme held at NIMBioS and Kirkpatrick's Four Levels of Evaluation model for training and learning programme (Kirkpatrick, 1994).

A pre/post evaluation survey measured self-reported changes in participant skills and knowledge as a result of taking part in the programme. We distributed a pre-programme self-evaluation survey to the students in April, and the pre-survey was again administered on the first day of the programme to ensure a $100 \%$ response rate. An identical survey was conducted towards the end of the programme. The summary of these surveys is shown in Table 4. Although the overall averages rose between the two surveys, the change was not entirely uniform. Seven of 8 students reported a net increase in confidence across the 17 survey categories. The greatest increase came from students with the lowest initial confidence (4 of 8) who increased self-reported confidence in 13 or more categories apiece. In exit discussions, the student with the outlying negative adjustment said that this reflected (1) a renormalization of pre-conceived notions held prior to the programme, and (2) a comparative assessment following interactions with students from other summer programmes at Duke, UNC Chapel Hill, Winthrop University, and North Carolina A\&T. 
Table 4. Student participants' self-evaluation where five is the highest and one is the lowest.

\begin{tabular}{lll}
\hline Skill/Knowledge of/Understanding of & $\begin{array}{c}\text { Confidence } \\
\text { level } \\
\text { pre-REU }\end{array}$ & $\begin{array}{c}\text { Confidence } \\
\text { level } \\
\text { post-REU }\end{array}$ \\
\hline Using research literature (e.g. journal articles, etc.) & 3.375 & 3.625 \\
Integrating scientific theories with research & 2.875 & 3.375 \\
Designing a research plan & 2.75 & 3.25 \\
Using mathematics to describe biological scenarios & 2.625 & 3.625 \\
Working collaboratively with other researchers & 4 & 4 \\
Analysing data & 3.125 & 3.75 \\
Interpreting results & 3.125 & 3.875 \\
Writing about results & 3.125 & 3.5 \\
Orally presenting results & 3.125 & 4 \\
How scientists work on real problems & 2.5 & 3.375 \\
The nature of the research process & 3.25 & 3.75 \\
Ethical issues in research & 3 & 3.375 \\
The nature of interdisciplinary research collaborations & 2.875 & 3.5 \\
How current research ideas build upon previous studies & 2.875 & 3.75 \\
The demands of a research career in your discipline & 3 & 4 \\
Possible career paths in your discipline & 2.875 & 3.75 \\
\hline
\end{tabular}

On 15 July 2014, Dr Lenhart visited our REU site and interviewed the student participants, graduate students, PIs and also the head of the Department of Mathematics and Statistics. Dr Lenhart concluded in her evaluation letter that this REU was outstanding and working effectively to achieve the programme's goals with strong departmental support. Dr Lenhart's report echoed the overall positive feedback about the REU experience that was provided by the undergraduate students, graduate students and PIs.

\section{Discussion}

The theme of our REU site was the evolution of cooperation, and this has been true not only in the nature of the research projects undertaken by the students but also in how our community of students, faculty and staff came together into a functioning whole. Beginning with the programme leadership, the faculty and graduate students each offered divergent experiences that we were able to apply towards the REU experience. The PI and co-PI both work with game theory in the course of their own research, but we approach problems with different mathematical techniques and address different contextual questions. This diversification manifested in the range of potential research topics that we were able to offer to the students. Additionally, by having graduate students from both the mathematical and biological sciences, participating students drew from the knowledge and customs of contrasting disciplines, something that is critically important for research and communication in mathematical biology.

The 2014 REU programme supported four distinct research programmes, two of which developed organically during the initial training phase. Each team encountered challenges with both the technical nature of the material plus internal group dynamics. In addition to programing, every student had to learn a new set of mathematical and modelling skills that were not part of their curricular background. The writing and presentation of research 
findings also were novel experiences for most of the students. Besides mastering the intellectual material pertaining to their respective projects, the students also had to negotiate a balance of the workload within their respective partnerships. This was a particularly common issue because summer goals (e.g. experience vs. publication) were at variance in three of the four research teams. Faculty and staff also had to adapt and manage expectations for how each project would progress over the summer.

Our REU students ultimately achieved quality results within the eight-week research phase. All four of the research projects have been or will be represented at a number of conferences with presentations in both the 2014 fall and 2015 spring semesters. Moreover, papers from all four projects will be submitted to professional peer-reviewed journals in the near term. At the time of this writing, two papers have already been submitted.

A primary goal that we held for the REU programme was promoting awareness of graduate opportunities in the mathematical and biological sciences. Our graduate students played an important role in mentoring the undergraduates on applying to graduate school and preparing supporting documents. Although the majority of our participants were underclassmen, there were two upperclassmen on whom we can already report affirmatively. One student has been accepted into a master's programme in mathematics beginning in spring 2015. The other student is presently applying to doctoral programmes for fall 2015 enrolment. A third student, not yet graduating, expressed her intention to pursue a $\mathrm{PhD}$ at UNCG. We will maintain contact with the remaining students as they matriculate in their majors and determine if they, too, pursue graduate studies.

We expect that the success of the UNCG REU programme will continue over the next two years of the grant, but we will implement some refinements based upon our experiences during the 2014 pilot year. The initial training period worked well to expose the students to a number of variations of 'biomathematics' and necessary academic skills. We will again offer a similar mix of short courses in 2015; however, there are a few content areas which we would like to modify and/or introduce. Our programing instruction needs to include specific training in reading legacy code, debugging, running simulations across parameter ranges and the visualization of results (e.g. flash-video or other animated export form). Additionally, the students reported that they felt rushed on the daily group projects which were used to encapsulate the lessons of the day. For the 2015 summer, we will integrate the assignments more directly within the programing course and give additional training to the graduate student working with that part of the programme.

Both the PI and co-PI were pleased with the inclusion of a weekly journal club, and we anticipate retaining this feature for 2015. The activity achieved the desired effect of making the students think about mathematical and biological exposition, and how researchers could take the same basic concept and ask very different questions (e.g. ecological and evolutionary consequences vs. the existence of global attractors or the permanence of quasispecies). Where the students demonstrated a noticeable deficiency early in the programme was in the communication of their own activities. They engaged in daily elevator talks and weekly presentations, but the students often struggled rhetorically with what they wanted to convey. With practice, however, they did improve and went on to make positive impressions speaking at various conferences. To further develop this aspect of our programme, we expect to offer on-going directed training throughout the summer on improving oration. In similar fashion, the manuscript writing process will be addressed earlier in the summer to facilitate student growth in this area.

The campus visitations were an excellent opportunity for exposure, but they were occasionally disruptive to the students' work efforts with respect to rapid turn-around scheduling or the need to spend the preceding day in preparation of giving talks. We 
recognize certain inherent limitations beyond our control when scheduling joint activities with other schools, but we will continue to optimize travel as best possible. Additionally, we will spend greater time on each campus and allow the students the opportunity to freely explore each university, further strengthening our primary goal for the REU. Finally, because our campus is rather vacant during the summer, our students expressed a sense of isolation from normal everyday activities. In response to this issue, we will include additional, regular social excursions to off-campus events and venues in our vicinity.

In summary, the UNCG REU had a very successful pilot year. We have planned some minor adjustments, but the basic structure and system that we have in place is strong, and we look forward to two more productive summers.

\section{Acknowledgements}

The authors would like to thank Olav Rueppell for his contributions to the 2014 REU programme. We would also like to thank Quinn Morris and Liz Bergen, who worked for the REU as graduate student assistants during the 2014 summer, Suzanne Lenhart, our external evaluator, and two anonymous reviewers.

\section{Disclosure statement}

No potential conflict of interest was reported by the authors.

\section{Funding}

The UNCG REU programme in Mathematical Biology is supported by the three-year National Science Foundation [grant number DMS-1359187] awarded to Rychtár, Rowell and Rueppell.

\section{References}

Broom, M., Hadjichrysanthou, C., \& Rychtár, J. (2010). Evolutionary games on graphs and the speed of the evolutionary process. Proceedings of the Royal Society A: Mathematical, Physical and Engineering Science, 466, 1327-1346.

Broom, M., \& Rychtár̆, J. (2013). Game-theoretical models in biology. CRC Press: Chapman \& Hall.

Cosner, C. (2005). A dynamic model for the ideal-free distribution as a partial differential equation. Theoretical Population Biology, 67, 101-108.

Fretwell, S. D., \& Lucas Jr., H. L. (1969). On territorial behavior and other factors influencing habitat distribution in birds. Acta Biotheoretica, 19, 16-36.

Ganter, S. (2003). Creating networks as vehicles for change. In L. A. Steen, \& B. L. Madison (Eds.), The future of quantitative literacy (pp.205-209). Princeton, NJ: National council on education and the disciplines.

Gillespie, D. T. (1976). A general method for numerically simulating the stochastic time evolution of coupled chemical reactions. Journal of Computational Physics, 22, 403-434.

Hofbauer, J., \& Sigmund, K. (1988). Evolutionary games and replicator dynamics. Cambridge: Cambridge University Press.

Kirkpatrick, D. L. (1994). Evaluating training programs: The four levels. San Francisco, CA: BerrettKoehler.

Lieberman, E., Hauert, C., \& Nowak, M. A. (2005). Evolutionary dynamics on graphs. Nature, 433, 312-316.

Lopatto, D. (2010). Science in solution: The impact of undergraduate research on student learning. Tucson, AZ: Research Corporation for Science Advancement. 
Nichols, H. B., Trentham-Dietz, A., Hampton, J. M., Titus-Ernstoff, L., Egan, K. M., Willett, W. C., $\&$ Newcomb, P. A. (2006). From menarche to menopause: Trends among us women born from 1912 to 1969. American Journal of Epidemiology, 164, 1003-1011.

Rowell, J. T. (2009). The limitation of species range: A consequence of searching along resource gradients. Theoretical Population Biology, 75, 216-227.

Rowell, J. T. (2010). Tactical population movements and distributions for ideally motivated competitors. American Naturalist, 176, 638-650.

Rowell, J. T., Ellner, S. P., \& Reeve, H. K. (2006). Why animals lie: How dishonesty can coexist in a signaling system. The American Naturalist, 168, E180-E204.

Russell, S., Hancock, M., \& McCullough, J. (2009). Benefits of undergraduate research experiences. The Pipeline, 316, 548-549. 